\title{
Reduced canine BRCA2 expression levels in mammary gland tumors
}

Yasunaga Yoshikawa ${ }^{1 *}$, Masami Morimatsu ${ }^{2}$, Kazuhiko Ochiai ${ }^{3}$, Toshina Ishiguro-Oonuma ${ }^{4}$, Seiichi Wada ${ }^{5}$, Koichi Orino ${ }^{1}$ and Kiyotaka Watanabe ${ }^{1}$

\begin{abstract}
Background: Mammary tumors are the most common tumor type in intact female dogs. Recently, the breast cancer 2 early onset (BRCA2) gene was proposed to be associated with tumorigenesis in dogs. The expression level of BRCA2 is important for its DNA repair function in mammalian cells, and its expression level is linked to tumorigenesis in mammary tissue. However, the expression of canine BRCA2 in mammary tumors is unclear.

Results: BRCA2 mRNA levels were compared between seven mammary gland samples and seventeen mammary tumor samples isolated from dogs. The expression level of canine BRCA2 in mammary tumor samples was lower than levels in mammary gland samples. We attempted to identify why the BRCA2 expression level was decreased in mammary tumor samples by promoter sequencing analysis; however, we did not find any mutations in the canine BRCA2 promoter that altered BRCA2 transcription levels. We did detect two types of BRCA2 splice variants in 8 mammary tumor samples. One of the variants induced a frame-shift mutation that could lead to nonsense-mediated mRNA decay, a ubiquitous cellular mechanism that eliminates mRNA containing a premature termination codon.

Conclusions: Reduced expression of canine BRCA2 mRNA in mammary tumor samples is a possible mechanism to explain mammary tumor development in dogs. One possible reason for reduced BRCA2 mRNA levels in these tumor samples was nonsense-mediated mRNA decay, not mutations in the BRCA2 promoter region. While it remains unclear why canine BRCA2 expression levels are reduced in mammary tumor samples, this study found that the expression level of BRCA2 was associated with canine mammary tumorigenesis.
\end{abstract}

Keywords: Splice variant, Nonsense-mediated mRNA decay, Premature termination codon, BRCA2 promoter, Promoter variation

\section{Background}

Mammary tumors are the most common tumor type in women, and they are also the most prevalent tumors in intact female dogs [1-4]. Mammary tumors constitute about half of all tumors in female dogs, and approximately half of canine mammary tumors are malignant $[5,6]$. In humans, inheritable breast cancers have been linked with mutations in the breast cancer susceptibility gene, breast cancer 2 early onset (BRCA2), and the lifetime risk of developing breast cancer is high (81-88\%) in females carrying a $B R C A 2$ mutation $[7,8]$. A recent study suggested that the canine $B R C A 2$ locus could also be associated with benign and malignant mammary

\footnotetext{
*Correspondence: yyoshika@vmas.kitasato-u.ac.jp

${ }^{1}$ Laboratory of Veterinary Biochemistry, School of Veterinary Medicine,

Kitasato University, Aomori 034-8628, Japan

Full list of author information is available at the end of the article
}

tumors. This study was based on a single nucleotide polymorphism analysis of an intronic marker [9]. In support of this notion, we previously showed loss of heterozygosity, a mechanism of BRCA2 inactivation, in a canine mammary tumor sample. Furthermore, canine $B R C A 2$ missense mutations, including some that affect BRCA2 function, were also reported in canine mammary tumors [10-13].

The BRCA2 protein is involved in homologous recombination repair via its interaction with RAD51 recombinase, and this function suppresses tumorigenesis. BRCA2 expression levels are important for preventing tumorigenesis, because cells with decreased expression of BRCA2 have heightened sensitivity to agents that induce DNA damage, such as DNA cross-linking agents and ionizing radiation $[14,15]$. In other words, the reduced BRCA2 expression leads to tumor formation. One 
of the most likely reasons why BRCA2 mRNA levels are reduced is a mutation in its promoter region. In humans, recent study showed that single nucleotide polymorphisms around the $B R C A 2$ gene affected the expression levels of human BRCA2 mRNA and increased breast cancer risk [16, 17].

Another pathway that may reduce BRCA2 expression is nonsense-mediated mRNA decay (NMD), a ubiquitous cellular mechanism that eliminates mRNAs containing premature termination codons (PTCs) to prevent the synthesis of potentially harmful truncated proteins [18]. Nonsense mutations and splice variants inducing frameshift mutations downstream of BRCA2 lead to PTC. Some PTC-induced mutations in human BRCA2 were associated with NMD [19].

However, in canine mammary tumors, little is known about BRCA2 expression. In this study, we found reduced BRCA2 mRNA expression levels in canine mammary tumors. To determine the reason why BRCA2 expression was decreased in canine mammary tumors, we performed a mutation analysis of the canine $B R C A 2$ promoter region and splice variants, the transcript of which may lead to PTC and NMD.

\section{Results}

\section{Reduced BRCA2 expression levels in canine mammary} tumors

The expression levels of tumor suppressor genes such as BRCA2 are important for preventing tumorigenesis in mammary cells. Thus, we hypothesized that tumorigenesis may be associated with low levels of BRCA2 expression. We first tested the expression levels of canine BRCA2 in mammary gland and mammary tumor samples by qRT-PCR. We designed primers for exons 26 and 27, the last two exons of canine BRCA2. As expected, the BRCA2 expression level in canine mammary tumors was significantly lower than the level in normal mammary gland tissues (Fig. 1).

\section{Mutation and promoter activity analyses in the canine $B R C A 2$ promoter region in mammary tumor samples}

One possible reason for reduced canine BRCA2 expression is a mutation in the canine $B R C A 2$ promoter region. However, the promoter region of canine BRCA2 was never studied. Therefore, we first determined the canine BRCA2 promoter region. In humans, the genomic region from -187 bp to +310 bp at the BRCA2 locus was reported as $B R C A 2$ promoter [20]. The putative canine BRCA2 promoter region (-259 bp to $+305 \mathrm{bp}$ ), which included the region corresponding to the human $B R C A 2$ promoter, was first cloned into the non-promoter pGL4 vector, encoding firefly luciferase (Additional file 1 : Figure S1). Luciferase activity in this putative canine $B R C A 2$ region was comparable to that at the human

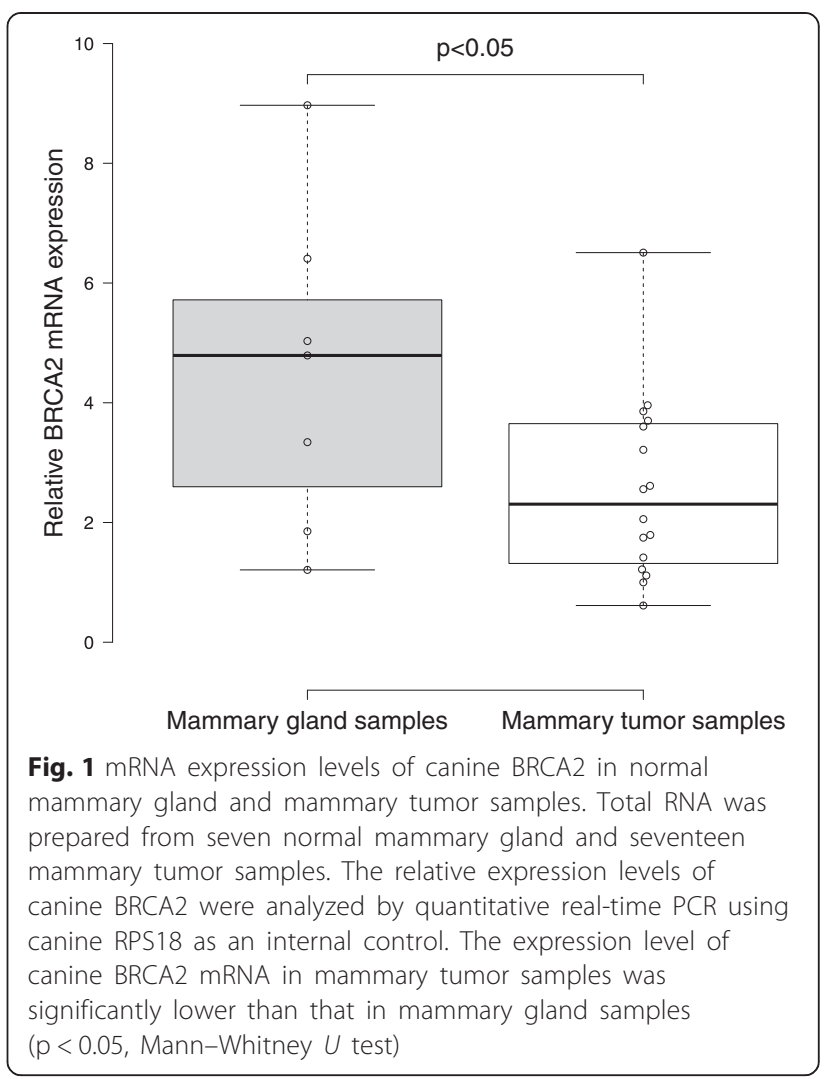

$B R C A 2$ promoter (Fig. 2). Thus, we concluded that this putative promoter of canine $B R C A 2$ functioned as the true canine $B R C A 2$ promoter.

We next performed a mutation analysis of the BRCA2 promoter region in the canine mammary tumor samples. We sequenced the DNA within this region and identified 9 allele types in canine mammary tumor samples (Table 1; genotypes of each tumor sample are shown in Additional file 2: Table S1). These variations were located in the putative cis-element, which corresponds to the site necessary for human BRCA2 expression (Additional file 1 Figure S1). We next investigated the effects of these variations on canine $B R C A 2$ promoter activity using a luciferase reporter assay. However, none of these variations affected the activity of the canine $B R C A 2$ promoter with or without DNA damage by X-ray irradiation (Fig. 3 a and b).

\section{Detection of splice variants}

Another reason for decreased mRNA expression is NMD, a ubiquitous cellular mechanism that eliminates PTC containing mRNAs to prevent the synthesis of truncated proteins that may be detrimental to cells [18]. One of the causes of PTC is a frame shift mutation induced by a splice variant. We next attempted to detect BRCA2 splice variants, which may contain frame-shift mutations, in mammary tumor samples using a modified 


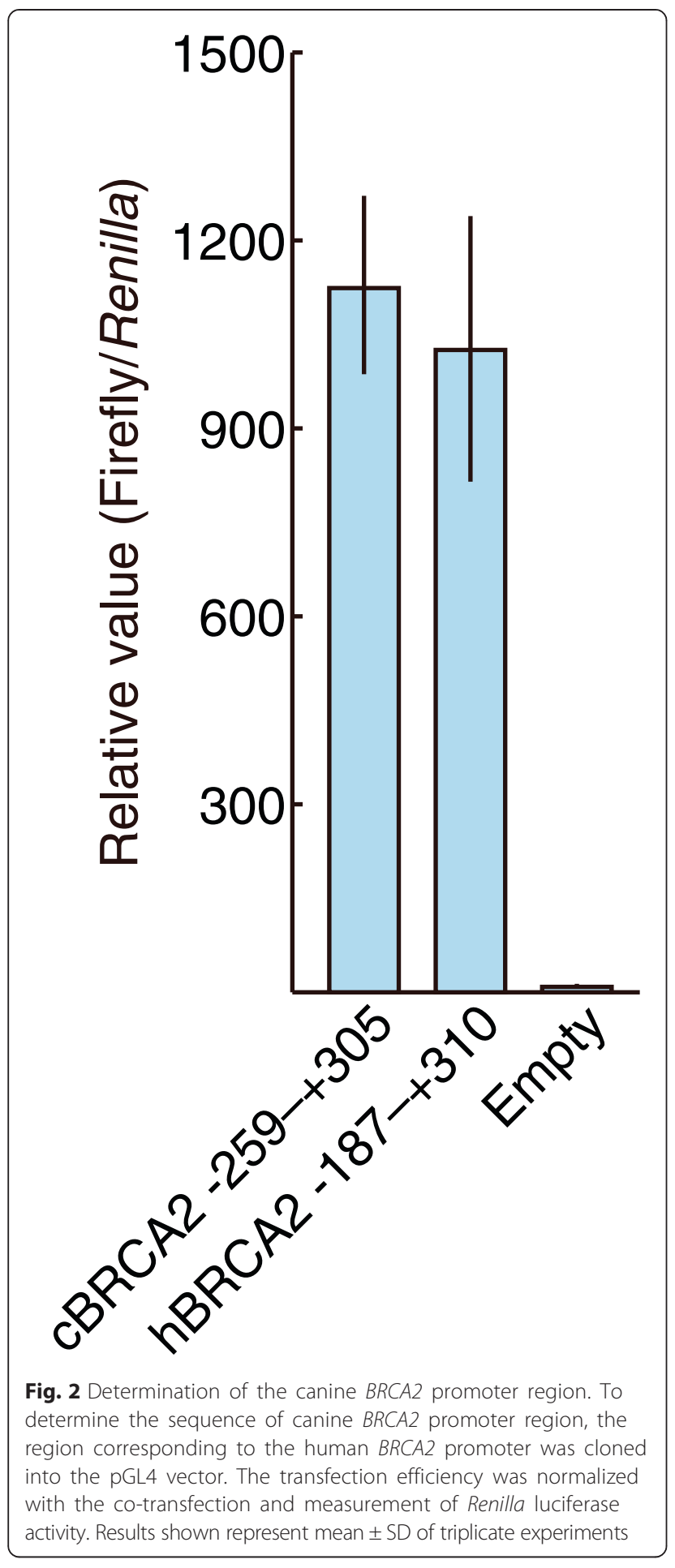

method that we reported previously [21]. In our previous study, we established primer sets to detect splice variants of canine BRCA2. In this study, we chose a primer set that amplified the region encoding exons 11 to 18 . This region was chosen because splice variants have been detected for a homologous region in human
$B R C A 2$, and we speculated that canine mammary tumors might show a similar result $[22,23]$. Indeed, we detected two splice variants: one lacking exons 14-16, and the other lacking exons 12 and 14. The variant lacking exons 12 and 14 showed a frame-shift mutation and PTC in 1 out of 17 canine mammary tumor samples (Fig. 4). In two mammary tumor samples (MT-2 and MT-11), the expression level of the splice variant was comparable to that of the wild-type splicing form. Surprisingly, even in the PCR products from normal canine mammary gland tissues, we detected a faint signal of the splice variants (these transcripts lacked exon 12, 14, or 13-16); however, the wild-type splicing form accounted for the majority of mRNA transcripts.

We also sequenced exon-intron boundary region of the 8 mammary tumor samples where splice variants were detected, as mutations at these boundaries induce splice variants. However, there were no mutations in these regions in any of the 8 tumor samples analyzed.

\section{Discussion}

Reduced BRCA2 expression disrupts homologous DNA recombination repair mechanisms, leading to tumor formation $[14,15]$. In this study, we compared the expression levels of canine BRCA2 in mammary gland tissue and mammary tumor samples. We found that BRCA2 expression was significantly reduced in mammary tumor samples compared to mammary gland samples. These results suggested that the low expression of canine BRCA2 may be related to mammary tumor development in dogs.

We further investigated possible reasons why canine BRCA2 expression was reduced in tumor samples: mutations in the BRCA2 promoter region and non-sense mRNA decay (NMD) induced by PTCs that can form in splice variants. To do this, we first identified and sequenced the canine $B R C A 2$ promoter region. We found that some cis-elements in human $B R C A 2$ promoter were not conserved. This suggests that regulatory mechanisms controlling BRCA2 transcription are different in dogs or perhaps that there are unknown cis-elements in the canine and human BRCA2 promoters [24, 25]. Regardless the differences in cis-elements between the canine and human $B R C A 2$ promoter region, we found that the promoter activity of the canine $B R C A 2$ promoter was comparable with human $B R C A 2$ promoter. A $B R C A 2$ promoter sequence analysis of mammary tumors revealed nine promoter allele types. Interestingly, these variations were located near the corresponding site of a human BRCA2 cis-element; however, none of the alleles disrupted canine BRCA2 promoter activity, including in cases with DNA damage by X-ray irradiation. These results led us to conclude that the nine alleles harbored 
Table 1 Promoter region allele types in mammary tumor samples

\begin{tabular}{|c|c|c|c|c|c|c|c|c|c|}
\hline \multirow{2}{*}{$\begin{array}{l}\text { Allele } \\
\text { type }\end{array}$} & \multicolumn{8}{|c|}{ Base sequence } & \multirow{2}{*}{$\begin{array}{l}\text { Allele } \\
\text { frequency }\end{array}$} \\
\hline & -162 & -156 & -118 & -117 & -100 & -95 & -37 & +9 & \\
\hline A type & - & - & - & - & - & - & - & - & $11 / 34$ \\
\hline B type & - & C & - & - & - & - & - & - & $5 / 34$ \\
\hline C type & - & - & - & - & - & - & $\mathrm{T}$ & - & $3 / 34$ \\
\hline D type & - & C & - & - & - & - & $\mathrm{T}$ & - & $4 / 34$ \\
\hline E type & - & C & delCGCCCCGC & - & - & - & - & - & $1 / 34$ \\
\hline F type & - & - & delCGCCCCGC & - & - & - & $\mathrm{T}$ & - & $3 / 34$ \\
\hline G type & A & - & delCGCCCCGC & - & - & - & $\mathrm{T}$ & - & $4 / 34$ \\
\hline H type & A & - & - & - & delTGCCCCC & - & - & - & $1 / 34$ \\
\hline I type & - & - & - & delGCCCCGT & - & delCCTGCCCCCTGCCC & $\mathrm{T}$ & delCGGCGG & $2 / 34$ \\
\hline
\end{tabular}

neutral mutations and that they were not associated with tumorigenesis.

We also explored whether the NMD system induced by PTCs could account for reductions in BRCA2 levels. One way to form PTCs is through splice variants. Detection of splice variants is more efficient than analyzing the entire BRCA2 sequence because BRCA2 is a large gene product (more than $11 \mathrm{kbp}$ ). We detected splice variants in 8 out of 17 canine mammary tumor samples and 5 out of 7 normal mammary gland samples. In two of the mammary gland samples, the expression level of the splice variants was comparable to that of the wildtype splicing form. Because, one of the splice variants lacking exons 12 and 14 induced frame-shift and PTC, it is possible that canine BRCA2 mRNA levels were reduced by these splice variants inducing PTC and the NMD system. Although this splice variant would not affect the mRNA levels of canine BRCA2, the transcripts would not have nuclear localization signals located at the C-terminal and would not function in the nuclei $[26,27]$. Because the most important function of BRCA2 is DNA repair in the nuclei, another possibility is that the splice variant lacking exons $14-16$ is associated with mammary tumors. The splice variant lacking exons 14-16 does not induce PTC. Its transcript lacks the front part of helical domain, where BRCA2 interacts with DSS1, a stabilizer $[28,29]$. Thus, the transcript from the splice variant lacking exons 14-16 would be unstable and could be associated with mammary tumors.

One of variant transcripts found in mammary gland samples was missing exon 12; this variant was also reported in human BRCA2 [22]. Exon 12 encodes a 96 bp region of both canine and human $B R C A 2$; therefore, this particular splice variant does not induce a frame-shift mutation. Human BRCA2 transcripts missing exon 12 did not have any effect on DNA repair activity. Thus, it was suggested that canine $B R C A 2$ transcripts missing exon 12 did not affect its function and expression levels. The expression levels of the other two splice variants, which were missing exon 14 or exons $13-16$, were very low compared to that of wild-type transcripts. We assumed that the low expression level of these splice variants did not affect BRCA2 mRNA expression. We also tried to determine the presence of mutations in the exon-intron boundary regions of the $B R C A 2$ transcripts, which is the most likely reason for the existence of splice variants. However, we did not detect any mutations in these regions. This result suggested that the splicing machinery might not function properly, resulting in BRCA2 splice variants.

Other reasons for the reduction in canine BRCA2 mRNA levels are still unclear. One possible explanation may be unregulated miRNA expression. Recently, the discovery of some miRNAs regulating BRCA2 expression levels were linked to breast cancer development in humans [30]. Therefore, it is possible that the expression of miRNAs could decrease canine BRCA2 expression at the mRNA level; however, it is unknown whether the same miRNA mechanism regulating human BRCA2 expression is functional in canines. Further studies are needed to address this issue.

Further studies are needed to reveal the correlation between canine BRCA2 transcript and protein levels in mammary tumor samples. Unfortunately, in this study, we collected mammary tumor samples soaked in RNAlater solution; therefore, we could only test BRCA2 mRNA levels and could not determine BRCA2 protein levels by western blotting or immunohistochemistry. In future studies, mammary tumor samples should be collected in two batches: one for RNA extraction and the other for western blotting or immunohistochemistry.

\section{Conclusions}

In this study, we showed that canine BRCA2 mRNA transcript levels were significantly reduced in mammary tumor samples compared to normal mammary gland 


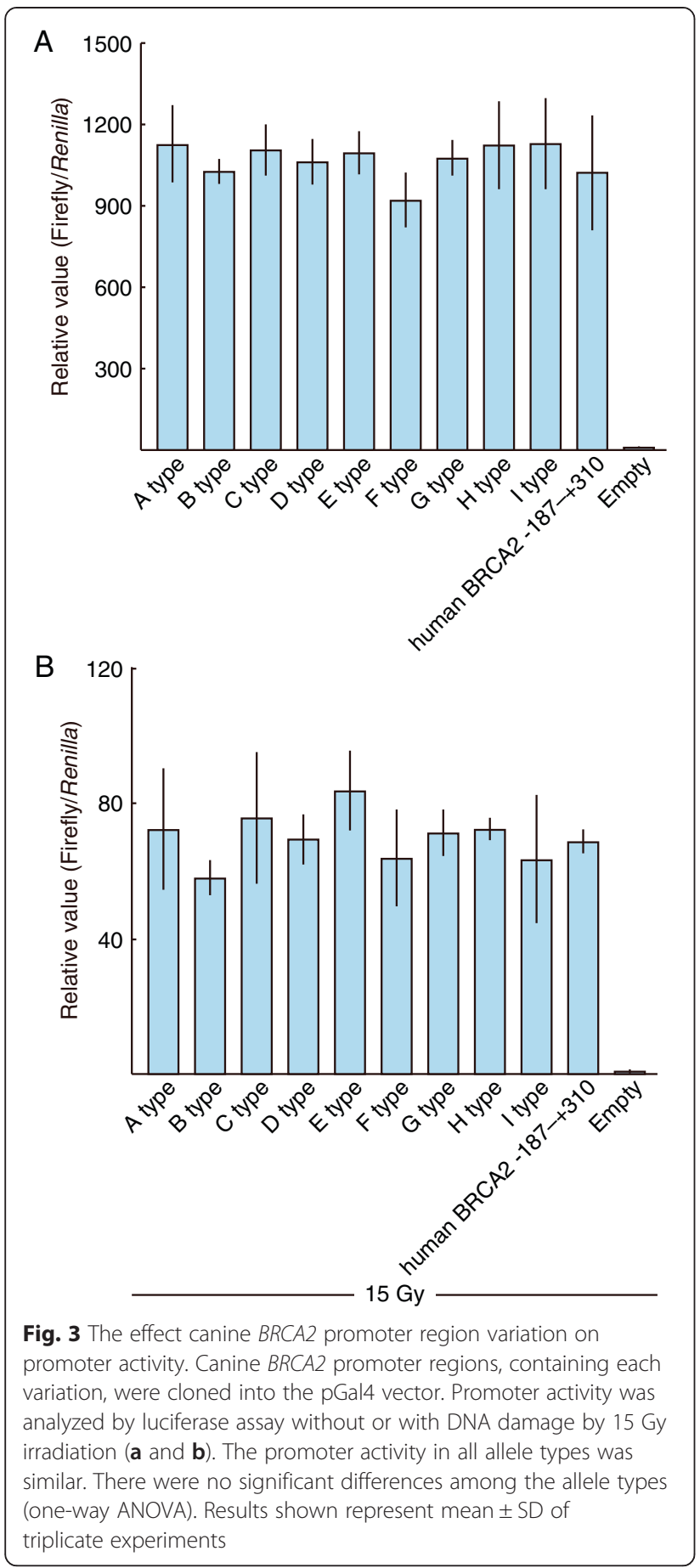

tissue. One of the reasons for reduced BRCA2 expression was nonsense-mediated mRNA decay (NMD), a ubiquitous cellular mechanism that eliminates premature termination codon that can be found in splice variants. Our results suggested that low BRCA2 expression in canine mammary tumors is a possible mechanism that leads to tumorigenesis. However, we still need to elucidate the mechanisms that regulate BRCA2 expression levels, and how low BRCA2 expression leads to the development of canine mammary tumors.

\section{Methods}

Mammary gland and tumor samples

Seven mammary gland samples and 17 mammary tumor samples were obtained from the veterinary hospitals of Iwate University and Kitasato University. These samples were stored at $-20{ }^{\circ} \mathrm{C}$ in RNAlater solution (Life Technologies) until processed for DNA or RNA extraction. All experimental procedures were approved by and conducted in accordance with the Guidelines for Institutional Laboratory Animal Care and Use of the School of Veterinary Medicine at Kitasato University, Japan (Approval Number: 11-065).

\section{Quantitative real-time PCR}

RNA extraction and cDNA synthesis were performed as previously described [21]. Quantitative real-time polymerase chain reaction (qRT-PCR) was carried out on StepOnePlus Real-Time PCR systems (Life Technologies) using KAPA SYBR FAST qPCR Kit (Kapa Biosystems) and $200 \mathrm{nM}$ of each primer (Additional file 3: Table S2). The PCR cycling conditions were as follows: $95{ }^{\circ} \mathrm{C}$ for $20 \mathrm{~s}$ followed by 40 PCR cycles of $95{ }^{\circ} \mathrm{C}$ for $3 \mathrm{~s}$ and $60^{\circ} \mathrm{C}$ for $30 \mathrm{~s}$. Melting curves were generated at the end of each real-time PCR run to ensure that a single specific product was amplified. Each sample was run in triplicate. The housekeeping gene canine RPS18 was used as internal references for normalization.

\section{Genomic PCR and Sequence analysis}

DNA extraction was performed as previously described [21]. To amplify the canine and human BRCA2 promoter region, each reaction mixture contained 10-50 ng of genomic DNA as a template, each forward and reverse primer (Additional file 3: Table S2) at $300 \mathrm{nM}$, $200 \mu \mathrm{M}$ dNTPs, $0.02 \mathrm{U}$ of KOD FX DNA polymerase (Toyobo, Japan), and 1x PCR buffer, which was supplied with the enzyme, in a total volume of $10 \mu \mathrm{l}$. PCR conditions included one cycle of $2 \mathrm{~min}$ at $94{ }^{\circ} \mathrm{C}$, followed by 35 cycles of $10 \mathrm{~s}$ at $98{ }^{\circ} \mathrm{C}, 15 \mathrm{~s}$ at the appropriate temperature for primer annealing, $1 \mathrm{~min}$ at $68^{\circ} \mathrm{C}$, and a final extension step of $7 \mathrm{~min}$ at $68^{\circ} \mathrm{C}$. The PCR products were treated with shrimp alkaline phosphatase (Affymetrix, Santa Clara, CA) and Exonuclease I (New England BioLabs, Beverley, MA) before sequencing. Direct DNA sequencing was performed at least twice for each amplicon. For some PCR products with heterozygous deletion mutations, direct sequencing could not determine the DNA base sequence; instead, PCR products were cloned into a pMD20 vector (TaKaRa, Japan) and at least five independent clones were sequenced to determine the heterozygous insertion/deletion mutations. 


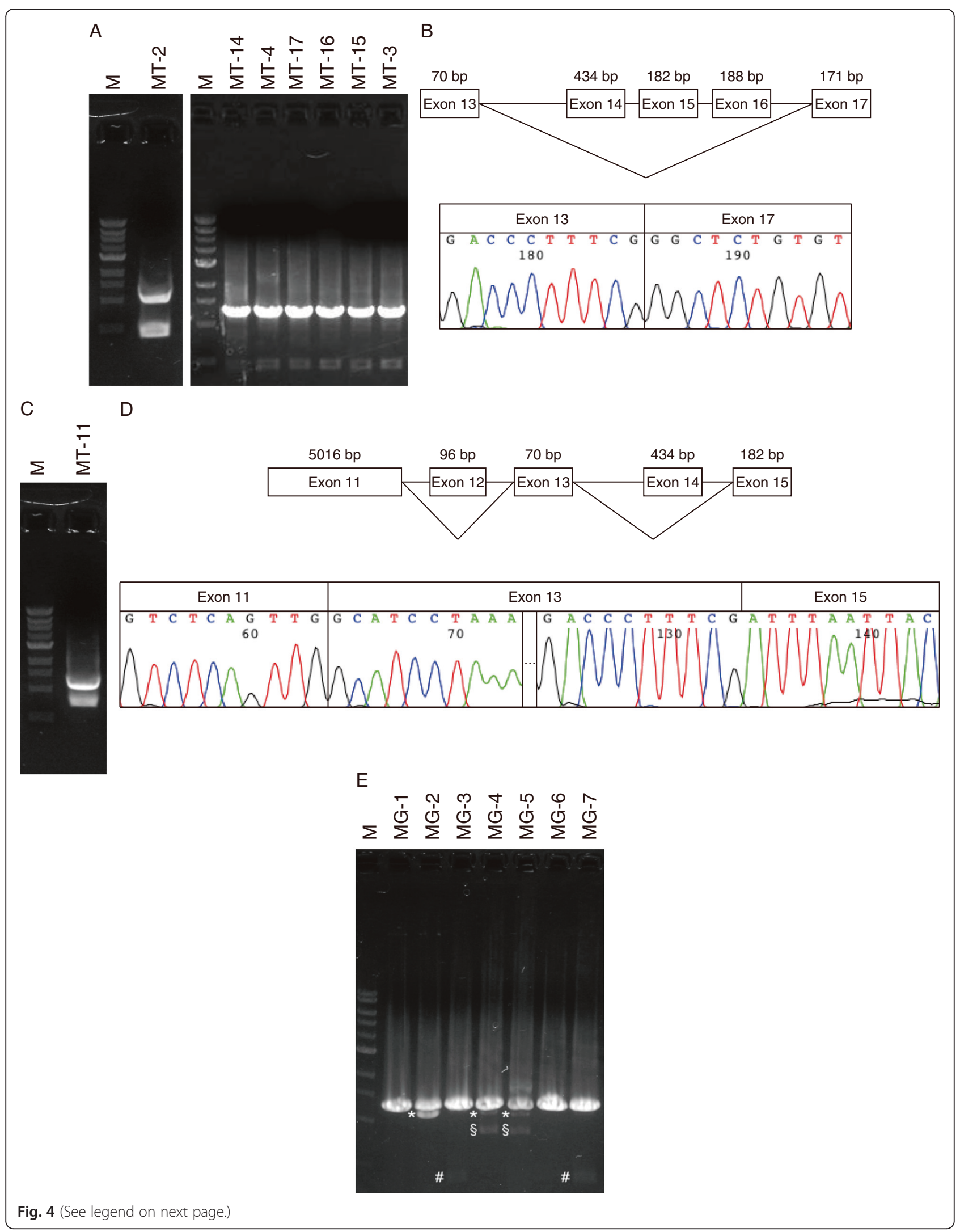


(See figure on previous page.)

Fig. 4 Detecting splice variants in mammary tumor and mammary gland samples. a Splice variants missing exons 14-16 were detected in mammary tumor samples. The left panel shows the PCR products detected by $1 \%$ agarose gel electrophoresis, and the right panel shows the DNA sequence chromatogram. b Splice variant missing exons 12 and 14 were detected in mammary tumor samples. The left panel shows the PCR products detected by $1 \%$ agarose gel electrophoresis, and the right panel shows the DNA sequence chromatogram. c Splice variants detected in mammary gland samples. Symbols are as follows: ${ }^{*}$, splice variant missing exon 12; $\S$, splice variant missing exon 14 ; \#, splice variant missing exons 13-16

\section{Luciferase assay}

For analysis of promoter activity using luciferase, the canine and human $B R C A 2$ promoter regions were cloned into pGL4 plasmids (Promega, U.S.A.). Approximately $2 \times 10^{5} \mathrm{HeLa}$ cells were transiently cotransfected with $100 \mathrm{ng}$ pGAL4 and $1 \mathrm{ng}$ pRL-TK (Promega) using FuGENE HD transfection reagent (Roche Diagnostics, Basel, Switzerland). Forty-eight hours after transfection, the cells were lysed in passive lysis buffer (Promega). Firefly and Renilla luciferase activity was measured using the DualLuciferase Reporter Assay Kit (Promega) according to the manufacturer's instructions. The transfection efficiency was normalized by measuring the Renilla luciferase activity.

To test the DNA damage caused by X-ray irradiation, at $3 \mathrm{~h}$ after transfection the cells were irradiated with 15 Gy and the irradiated cells were harvested $15 \mathrm{~h}$ later.

\section{Detection of splice variants}

To detect splice variants and determine the DNA sequences of exons 11-26, including the exon-intron boundary region in canine $B R C A 2$, the target regions were amplified and sequenced as described previously [21]. However, the DNA samples derived from mammary tumors did not amplify in the first PCR reaction, thus in these samples, nested PCR was performed using a second primer set (Additional file 3: Table S2). The nucleotide sequence of these PCR products was determined by direct sequencing.

\section{Statistical analysis}

To compare the canine BRCA2 mRNA expression level between mammary grand and mammary tumor samples, the Mann-Whitney $U$-test was used. For comparison of canine BRCA2 promoter activity among variants, one-way Analysis of Variance (ANOVA) tests were used.

\section{Additional files}

Additional file 1: Figure S1. Alignment of the canine and human $B R C A 2$ promoter regions. To identify the canine BRCA2 promoter region, the putative promoter region was aligned with the human $B R C A 2$ promoter. Boxes indicate important cis-elements in the human BRCA2 promoter region. Arrowheads indicate the sites where we identified variations in mammary tumor samples.

Additional file 2: Table S1. Genotype of canine BRCA2 in mammary tumor samples.

Additional file 3: Table S2. Primer sets used in this study.

\section{Competing interests}

The authors declare that they have no competing interests.

\section{Author contributions}

YY outlined the design and coordinated the study, performed the experiments, and drafted the manuscript. MM, K. Ochiai, TO, SW, K. Orino, and KW performed several experiments, participated in the design of the study, and helped to draft the manuscript. All authors read and approved the final manuscript.

\section{Acknowledgements}

This work was supported in part by a Kitasato University Research Grant for Young Researchers and Grants-in-Aid for Young Scientists (B) (No. 23780326 and No. 24780313) and Scientific Research (C) (No. 26450400) from the Japan Society for the Promotion of Science.

\section{Author details}

${ }^{1}$ Laboratory of Veterinary Biochemistry, School of Veterinary Medicine, Kitasato University, Aomori 034-8628, Japan. ${ }^{2}$ Laboratory of Laboratory Animal Science and Medicine, Department of Disease Control, Graduate School of Veterinary Medicine, Hokkaido University, Sapporo 060-0818, Japan. ${ }^{3}$ Department of Basic Science, School of Veterinary Nursing and Technology, Nippon Veterinary and Life Science University, Tokyo 180-8602, Japan. ${ }^{4}$ Department of Biological Resources, Integrated Center for Science, Ehime University, Ehime 791-0295, Japan. ${ }^{5}$ Laboratory of Veterinary Radiology and Radiation Biology, School of Veterinary Medicine, Kitasato University, Aomori 034-8628, Japan.

Received: 2 February 2015 Accepted: 14 July 2015

Published online: 23 July 2015

\section{References}

1. Egenvall A, Bonnett BN, Ohagen P, Olson P, Hedhammar A, von Euler $\mathrm{H}$. Incidence of and survival after mammary tumors in a population of over 80,000 insured female dogs in Sweden from 1995 to 2002. Prev Vet Med. 2005;69(1-2):109-27.

2. Moe L. Population-based incidence of mammary tumours in some dog breeds. J Reprod Fertil Suppl. 2001;57:439-43.

3. Moulton JE, Rosenblatt LS, Goldman M. Mammary tumors in a colony of beagle dogs. Vet Pathol. 1986;23(6):741-9.

4. Siegel RL, Miller KD, Jemal A. Cancer statistics, 2015. CA Cancer J Clin. 2015;65(1):5-29.

5. Gilbertson SR, Kurzman ID, Zachrau RE, Hurvitz Al, Black MM. Canine mammary epithelial neoplasms: biologic implications of morphologic characteristics assessed in 232 dogs. Vet Pathol. 1983;20(2):127-42.

6. Moulton JE, Taylor DO, Dorn CR, Andersen AC. Canine mammary tumors. Pathol Vet. 1970;7(4):289-320.

7. Evans DG, Shenton A, Woodward E, Lalloo F, Howell A, Maher ER. Penetrance estimates for BRCA1 and BRCA2 based on genetic testing in a Clinical Cancer Genetics service setting: risks of breast/ovarian cancer quoted should reflect the cancer burden in the family. BMC Cancer. 2008;8:155. 
8. King MC, Marks JH, Mandell JB. Breast and ovarian cancer risks due to inherited mutations in BRCA1 and BRCA2. Science. 2003;302(5645):643-6.

9. Rivera P, Melin M, Biagi T, Fall T, Haggstrom J, Lindblad-Toh K, et al. Mammary tumor development in dogs is associated with BRCA1 and BRCA2. Cancer Res. 2009;69(22):8770-4.

10. Ochiai K, Ishiguro-Oonuma T, Yoshikawa $Y$, Udagawa C, Kato $Y$, Watanabe $\mathrm{M}$, et al. Polymorphisms of canine BRCA2 BRC repeats affecting interaction with RAD51. Biomed Res. 2015;36(2):155-8.

11. Yoshikawa Y, Morimatsu M, Ochiai K, Nagano M, Tomioka Y, Sasaki N, et al. Novel variations and loss of heterozygosity of BRCA2 identified in a dog with mammary tumors. Am J Vet Res. 2008;69(10):1323-8.

12. Yoshikawa $Y$, Morimatsu M, Ochiai $K$, Nagano M, Yamane $Y$, Tomizawa $\mathrm{N}$, et al. Analysis of genetic variations in the exon 27 region of the canine BRCA2 locus. J Vet Med Sci. 2005;67(10):1013-7.

13. Yoshikawa $Y$, Ochiai $K$, Morimatsu M, Suzuki $Y$, Wada S, Taoda T, et al. Effects of the missense mutations in canine BRCA2 on BRC repeat 3 functions and comparative analyses between canine and human BRC repeat 3. PLoS One. 2012;7(10):e45833.

14. Arnold K, Kim M-K, Frerk K, Edler L, Savelyeva L, Schmezer P, et al. Lower level of BRCA2 protein in heterozygous mutation carriers is correlated with an increase in DNA double strand breaks and an impaired DSB repair. Cancer Lett. 2006;243(1):90-100.

15. Lee SA, Roques C, Magwood AC, Masson J-Y, Baker MD. Recovery of deficient homologous recombination in Brca2-depleted mouse cells by wild-type Rad51 expression. DNA Repair (Amst). 2009;8(2):170-81.

16. Maia AT, Antoniou AC, O'Reilly M, Samarajiwa S, Dunning M, Kartsonaki $C$, et al. Effects of BRCA2 cis-regulation in normal breast and cancer risk amongst BRCA2 mutation carriers. Breast Cancer Res. 2012;14(2):R63.

17. Liu L, Fang Y, Fan JL, Hu JM, Xu XT, Jin XH, et al. BRCA2 promoter polymorphism is associated with breast cancer prognosis in Chinese women. Chinese Med J-Peking. 2014;127(11):2012-5.

18. Popp MW, Maquat LE. Organizing principles of mammalian nonsensemediated mRNA decay. Annu Rev Genet. 2013:47:139-65.

19. Ware MD, DeSilva D, Sinilnikova OM, Stoppa-Lyonnet D, Tavtigian SV, Mazoyer S. Does nonsense-mediated mRNA decay explain the ovarian cancer cluster region of the BRCA2 gene? Oncogene. 2006;25(2):323-8.

20. Misra S, Sharma S, Agarwal A, Khedkar SV, Tripathi MK, Mittal MK, et al. Mol Cancer. 2010;9:50.

21. Yoshikawa Y, Morimatsu M, Ochiai K, Okuda K, Taoda T, Chikazawa S, et al. Establishment of a PCR analysis method for canine BRCA2. BMC Res Notes. 2012;5(1):173

22. Li L, Biswas K, Habib LA, Kuznetsov SG, Hamel N, Kirchhoff T, et al. Functional redundancy of exon 12 of $B R C A 2$ revealed by a comprehensive analysis of the c.6853A > G (p.12285V) variant. Hum Mutat. 2009;30(11):1543-50.

23. Spurdle AB, Lakhani SR, Da Silva LM, Balleine RL, Goldgar DE. Bayes analysis provides evidence of pathogenicity for the BRCA1 c.135-1G > T (IVS3-1) and BRCA2 C.7977-1G > C (IVS17-1) variants displaying in vitro splicing results of equivocal clinical significance. Hum Mutat. 2010;31(2):E1141-5.

24. Davis PL, Miron A, Andersen LM, Iglehart JD, Marks JR. Isolation and initial characterization of the BRCA2 promoter. Oncogene. 1999;18(44):6000-12.

25. Wu K, Jiang SW, Thangaraju M, Wu G, Couch FJ. Induction of the BRCA2 promoter by nuclear factor-kappa B. J Biol Chem. 2000;275(45):35548-56.

26. Yano K, Morotomi K, Saito H, Kato M, Matsuo F, Miki Y. Nuclear localization signals of the BRCA2 protein. Biochem Biophys Res Commun. 2000;270(1):171-5

27. Yoshikawa $Y$, Morimatsu M, Ochiai K, Nagano M, Yamane $Y$, Tomizawa N, et al. Insertion/deletion polymorphism in the BRCA2 nuclear localization signal. Biomed Res. 2005;26(3):109-16.

28. Yang $H$, Jeffrey PD, Miller J, Kinnucan E, Sun $Y$, Thoma NH, et al. BRCA2 function in DNA binding and recombination from a BRCA2-DSS1-sSDNA structure. Science. 2002;297(5588):1837-48.

29. Li J, Zou C, Bai Y, Wazer DE, Band V, Gao Q. DSS1 is required for the stability of BRCA2. Oncogene. 2006;25(8):1186-94.

30. Choi YE, Pan Y, Park E, Konstantinopoulos P, De S, D'Andrea A, et al. MicroRNAs down-regulate homologous recombination in the G1 phase of cycling cells to maintain genomic stability. eLife. 2014;3:e02445.

\section{Submit your next manuscript to BioMed Central and take full advantage of:}

- Convenient online submission

- Thorough peer review

- No space constraints or color figure charges

- Immediate publication on acceptance

- Inclusion in PubMed, CAS, Scopus and Google Scholar

- Research which is freely available for redistribution

Submit your manuscript at www.biomedcentral.com/submit 